\title{
A Comprehensive Evaluation of the Kinetic Method Applied in the Determination of the Proton Affinity of the Nucleic Acid Molecules
}

\author{
Leonardo Di Donna, Anna Napoli, and Giovanni Sindona \\ Department of Chemistry, University of Calabria, Arcavacata di Rende, Italy \\ Costantinos Athanassopoulos \\ Department of Chemistry, University of Patras, Patras, Greece
}

\begin{abstract}
The determination of proton affinity (PA) of 2'-deoxyadenosine (dA) is used as a case study for the evaluation of possible drawbacks in the determination of the PA of the nucleic acid molecules by the kinetic method. The observed $\triangle \mathrm{PA}$ among the different values obtain for $\mathrm{dA}$ by applying this procedure in its different extensions was $0.64 \mathrm{Kcal} / \mathrm{mol}$, which is within the uncertainties of any theoretical or experimental approach. It was demonstrated that nucleosides can be generally used as reference compounds to measure the PA of an unknown nucleoside. The evaluation of $\Delta \Delta \mathrm{S}$ value for two competing reaction channels taken by proton-bound heterodimers formed by two nucleosides provides clear information on the reference base which has to be discarded from the set of reference compounds used for the estimation of an unknown PA. The PA of dA obtained with the most elaborated kinetic method $(237.00 \pm 0.07 \mathrm{kcal} / \mathrm{mol})$ is consistent with the value of $237.0 \mathrm{kcal} / \mathrm{mol}$ obtained by a simple treatment of the relative intensities of the product ions generated by two couples of the proton bound dimers formed by the nucleoside and two reference amines. The kinetic method can be, therefore, confidently used to assess the proton affinity of the multifunctional molecules such as nucleosides and nucleobases. (J Am Soc Mass Spectrom 2004, 15, 1080-1086) @ 2004 American Society for Mass Spectrometry
\end{abstract}

$\mathrm{T}$ The exploitation of mass spectrometric methods in the structure determination of nucleic acid molecules is characterized by two fundamental papers. The oldest one, from the early 60 s by Biemann and coworkers [1], paved the way by establishing some guidance rules for the gas phase fragmentation of nucleosides radical cations produced by electron ionization. The other is a contribution by McLafferty and coworkers in the late 90s, where the composition of long stranded nucleic acids was determined by FT-ICR [2]. The fundamental reaction path of nucleoside radical cations, represented by the formation of charged nucleobases upon glycosidic bond scission, was taken also by protonated molecule, once they became available in the gas phase by desorption ionization methods [3-5]. Whereas the extremely high resolving power of an ICR instrument allowed to obtain the exact molecular weight of long oligomers, and thus the composition

Published online June 9, 2004

This article is dedicated to Professor F. W. McLafferty.

Address reprint requests to Dr. G. Sindona, Dipartimento di Chimica, Università della Calabria, Via P. Bucci cubo 12/C, I-87030, Arcavacata di Rende (CS), Italy. E-mail: sindona@uncial.it of the strand in terms of number and types of nucleobases [2,6].

A drawback in the sequence of unknown DNA strands is represented by the structure assumed by the oligomers upon ionization by desorption ionization and spray methods. The evaluation of the charge status of the $[\mathrm{M}-\mathrm{H}]^{-}$species released into the gas phase from singly stranded oligomers has been addressed since the early 80s. A zwitterionic form, suggested for tetramers [7] on the basis of the observed reactivity in a B-E sector instrument and later confirmed for similar species [8,9], might not correspond to the most stable gaseous structure among those available for singly charged species [10]. Nevertheless, Brønsted type equilibria drive the formation of charged gaseous oligonucleotide strands.

Therefore, in all the reports dealing with structure evaluation of DNA strands by mass spectrometry, the proton affinity (PA) of the nucleobases of a given oligomer was considered an important parameter to be taken into account.

The determination of the proton affinity of nucleosides [11-13] provides thermochemical quantities which have been extensively used [14] in the set-up of sequence rules for short oligonucleotides as well as for 


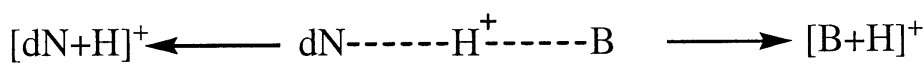

Scheme 1

theoretical applications [15]. Moreover the kinetic method [16], used for this type of application, is the only reliable experimental procedure for the evaluation of these important parameters. The method has been also exploited since the introduction of its basic version [17] to respond to criticisms arising from possible underestimation of entropy terms [18] in the evaluation of the reaction enthalpies for the competing breakdown proton-bound heterodimers and in particular of protonbound nucleosides $[19,20]$. In the following section the determination of the PA of 2-deoxyribofuranosyladenine (dA) will be carried out through all different available approaches, using different sets of reference compounds. The evaluation of thermodynamic parameters of $\mathrm{dA}$ represents, therefore, a case study which aims at validating the kinetic method when applied to nucleic acid molecules

\section{Experimental}

\section{ESI Experiments}

The Electrospray ionization (ESI) experiments were carried out in a hybrid Q-Star Pulsar-i (MSD Sciex Applied Biosystems, Toronto, Canada) mass spectrometer equipped with an ion spray ionization source. Samples were introduced by direct infusion $(5 \mu \mathrm{L} / \mathrm{min})$ of a solution containing the analyte $(10 \mathrm{pmol} / \mu \mathrm{L}$, dissolved in solution $0.1 \%$ acetic acid, methanol/water $50 / 50$ ) at the optimum ion spray voltage of $4800 \mathrm{~V}$. The nitrogen gas flow was set at 30 psi and the declustering and the focusing potentials were kept at 70 and $140 \mathrm{~V}$ relative to ground, respectively. $\mathrm{MS}^{2}$ experiments were performed in the collision cell $q$ on the isotopically pure $\left({ }^{12} \mathrm{C}\right)$ peak of the selected precursor ions by keeping the first quadrupole analyzer at $20 \mathrm{~V}$ relative to ground and operating at unit resolution, and scanning the time-offlight (TOF) analyzer. The gas pressure of the collision chamber was set at the instrumental parameters CAD 2, $3,4,5$, and 6 which corresponds to $9.48 \times 10^{-4}$, $2.84 \times 10^{-3}, 5.53 \times 10^{-3}, 6.16 \times 10^{-3}$, and $6.68 \times 10^{-3}$ torr and $6.26 \times 10^{14}, 1.88 \times 10^{15}, 3.50 \times 10^{15}, 4.07 \times 10^{15}$ and $4.65 \times 10^{15}$ molecules $/ \mathrm{cm}^{2}$ gas thickness, respectively. All the acquisitions were averaged over 60 scans at a TOF resolving power of 8000 with a standard deviation of $0.01 \mathrm{cps}$.

\section{FAB Experiments}

FAB experiments were performed using saturated solution $(1-2 \mu \mathrm{l})$ of $\mathrm{dA}$ with the appropriate reference base in glycerol. Mass spectra were obtained on a VG ZAB-2F mass spectrometer operating at an accelerating potential of $8 \mathrm{KeV}$ by using a standard FAB gun. A neutral Xe beam of $8 \mathrm{KeV}$ energy and a current of $\approx 10$ $\mu \mathrm{A}$ were employed. The spectra were recorded at 1000 resolution by scanning the magnetic field. The massanalyzed ion kinetic energy (MIKE) spectra were recorded by scanning upwards the electrostatic sector potential.

\section{Results and Discussion}

In the first application of the kinetic method [17] to nucleic acids [11, 12], the PA of 2'-deoxynucleosides was evaluated using tertiary amines as reference compounds to prevent multiple hydrogen bond interaction, likely occurring within the protonated heterodimers.

The availability of multiple prion sites on a given nucleoside and the possible interaction through multiple hydrogen bonds with some reference compounds [20] may affect the correct evaluation, by the adopted method, of the reaction enthalpies of the two competing dissociation pathways taken by the protonated heterodimers (Scheme 1).

A set of tertiary amines (Table 1), larger than that used in the original application [11], was chosen for re-evaluating the proton affinity of $2^{\prime}$-deoxyadenosine, by different approaches.

Saturated solutions of $\mathrm{dA}$ and a given reference amine (B) in glycerol afforded by FAB the hetero- and homo-dimers $[\mathrm{dA}+\mathrm{H}+\mathrm{B}]^{+},[\mathrm{dA}+\mathrm{H}+\mathrm{dA}]^{+},[$Ado $+\mathrm{H}+\mathrm{B}]^{+}$, being Ado the nucleobase adenine. The MIKE spectrum of $[\mathrm{dA}+\mathrm{H}+\mathrm{B}]^{+}$species showed the protonated species $[\mathrm{dA}+\mathrm{H}]^{+}$and $[\mathrm{B}+\mathrm{H}]^{+}$, as the exclusive product ions whose relative intensity (Table 1) provided the ratio of the relative dissociation constants $\mathrm{k}_{\mathrm{dA}} / \mathrm{k}_{\mathrm{B}}$, used to evaluate the PA by applying eq 1. The PA values obtained for $d A$ using the pairs (dA-TPA)/(dA-TEA), (dA-DIPEA)/(dA-TEA), and (dA-DIPEA)/(dA-TPA) were $237.02,237.07$, and 237.04 $\mathrm{kcal} / \mathrm{mol}$, respectively, with an average value of 237.04 $\mathrm{kcal} / \mathrm{mol}$. The same $\mathrm{k}_{\mathrm{dA}} / \mathrm{k}_{\mathrm{B}}$ values have been used also

Table 1. FAB-MIKE spectra of proton-bound heterodimers formed by dA and tertiary amines (B). The relative abundance of protonated species is reported

\begin{tabular}{lccccc}
\hline DA & TEA & TPA & DIPEA & TBA & TPEA \\
\hline \hline 90.9 & 9.1 & & & & \\
52.9 & & 47.1 & & & \\
59.9 & & & 40.1 & & \\
19.0 & & & & 81.0 & \\
97.1 & & & & & 2.9 \\
\hline
\end{tabular}

dA (2'-deoxyadenosine); TEA (triethylamine, $\mathrm{PA}=234.6 \mathrm{kcal} / \mathrm{mol}$ ) [i]; TPA (tripropilamine, PA $=236.9 \mathrm{kcal} / \mathrm{mol}$ ) [21]; TBA (tributylamine, PA $=238.9 \mathrm{kcal} / \mathrm{mol}$ ) [21]; DIPEA (diisopropilethylamine, $\mathrm{PA}=237.5$ $\mathrm{kcal} / \mathrm{mol}$ ) [21] and TPEA (Tripentylamine, PA $=238.8 \mathrm{kcal} / \mathrm{mol}$ ) [21]. 
Table 2. FAB-MIKE spectra of proton-bound heterodimers formed by $\mathrm{dA}$ and different nucleosides $(\mathrm{N})$. The relative abundance of protonated species is reported

\begin{tabular}{llllll}
\hline $\mathrm{dA}$ & $\mathrm{dC}$ & $\mathrm{DdC}$ & $\mathrm{ddA}$ & $\mathrm{dG}$ & $\mathrm{A}$ \\
\hline \hline 73.6 & 26.4 & & & & \\
27.6 & & 72.4 & & & \\
17.0 & & & 83.0 & & \\
51.8 & & & & 48.2 & \\
80.0 & & & & & 20.0 \\
\hline
\end{tabular}

$\mathrm{dC}(\mathrm{PA}=236.2 \mathrm{kcal} / \mathrm{mol})$ [13]; ddC (PA = $237.6 \mathrm{kcal} / \mathrm{mol})$ [13]; ddA (PA $=237.9 \mathrm{kcal} / \mathrm{mol})[13] ; \mathrm{dG}(\mathrm{PA}=237.4 \mathrm{kcal} / \mathrm{mol})$ [21]; $\mathrm{A}(\mathrm{PA}=236.4$ $\mathrm{kcal} / \mathrm{mol}[13]$

to evaluate the PA by means of eq 2, i.e., by plotting the proton affinity of the reference compounds versus $\ln \left(\mathrm{k}_{\mathrm{dA}} / \mathrm{k}_{\mathrm{B}}\right)$ for each cluster. Both methods provide consistent values with a difference of less than $0.10 \mathrm{kcal} /$ mol.

$$
P A=\frac{\left[\ln \left(k / k_{B 1}\right)\right] P A_{B 2}-\left[\ln \left(k / k_{B 2}\right)\right] P A_{B 1}}{\left.\left.\left[\ln \left(k / k_{B 1}\right)\right]-\right] \ln \left(k / k_{B 2}\right)\right]}
$$

$$
\ln \left(k / k_{\text {ref }}\right)=-\Delta S / R+\Delta P A / R T_{\text {eff }} ; \quad \Delta S=0
$$

$[22,23]$

$$
\begin{aligned}
y= & \Delta G^{a p p} / R T_{e f f} \\
= & -\left(\Delta S^{\mp} / R\right)+\left[\left(P A / R T_{e f f}\right)\right. \\
& \left.-\left(P A_{a v g} / R T_{e f f}\right)\right] m=1 / R T_{e f f}
\end{aligned}
$$

[24].

Preliminary results $[13,19]$ have shown that nucleosides themselves can be used as references compounds (N) for the evaluation of the PA of unknown nucleosides.

Accordingly, the set of proton bound dimers between $\mathrm{dA}$ and $2^{\prime}, 3^{\prime}$-ddC ( $2^{\prime}, 3^{\prime}$-dideoxycytidine), $2^{\prime}, 3^{\prime}$ ddA ( $2^{\prime}, 3^{\prime}$-dideoxyadenosine), $2^{\prime}$-dC (2'-deoxycytidine), A (adenosine) and $2^{\prime}-\mathrm{dG}$ ( $2^{\prime}$-deoxyguanosine) were produced by FAB. The occurring of different protonation sites within the same nucleobase could lead to a mixture of proton-bound isobaric dimmers [25] or in some particular cases, to the formation of multiple hydrogen bonded species [20].

The unimolecular dissociation of $[\mathrm{N}+\mathrm{H}+\mathrm{dA}]^{+}$ species (Table 2) yields protonated monomers only. The ratio $\mathrm{k}_{\mathrm{dA}} / \mathrm{k}_{\mathrm{N}}$ is again used to determine the PA values of $\mathrm{dA}$ by eqs 1 and 2 .

From the data reported in Table 2, the values of $236.88,237.11$, and 237.13 are obtained by applying eq 1 to the pairs $(\mathrm{dA}-\mathrm{dC}) /(\mathrm{dA}-\mathrm{ddA}),(\mathrm{dA}-\mathrm{ddC}) /(\mathrm{dA}-\mathrm{A})$, and $(\mathrm{dA}-\mathrm{ddC}) /(\mathrm{dA}-\mathrm{ddA})$, respectively, with an average value of $237.04 \pm 0.14 \mathrm{kcal} / \mathrm{mol}$.

If the $\mathrm{dG}$ value (Table 2 ) is included in the evaluation

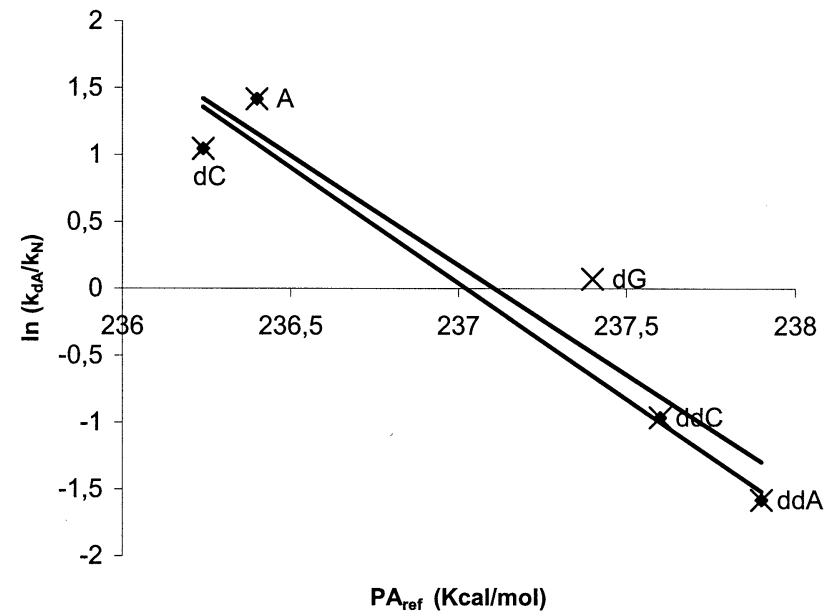

Figure 1. Kinetic method plots for the determination of the proton affinity of dA based eq 2 .

of the PA, the values of $237.49,237.45,237.42$ and 237.41 $\mathrm{kcal} / \mathrm{mol}$ are obtained by applying eq 1 to the pairs $(\mathrm{dA}-\mathrm{dC}) /(\mathrm{dA}-\mathrm{dG}), \quad(\mathrm{dA}-\mathrm{dG}) /(\mathrm{dA}-\mathrm{A}), \quad(\mathrm{dA}-\mathrm{dG}) /(\mathrm{dA}-$ $\mathrm{dd} A)$, and $(\mathrm{dA}-\mathrm{dG}) /(\mathrm{dA}-\mathrm{ddC})$ respectively, providing an average value of $237.44 \pm 0.04 \mathrm{kcal} / \mathrm{mol}$.

When eq 2 is applied, two linear correlation plots of PA versus $\ln \left(\mathrm{k}_{\mathrm{dA}} / \mathrm{k}_{\mathrm{N}}\right)$, i.e., $\mathrm{y}=-1.6353 \mathrm{x}+387.75\left(\mathrm{R}^{2}=\right.$ $0,9059)$ and $y=-1.7311 x+410.3\left(R^{2}=0.9671\right)$, are obtained if $\mathrm{dG}$ data are included or excluded, respectively (Figure 1). Accordingly, the PA values of 237.11 and of $237.02 \mathrm{kcal} / \mathrm{mol}$ can be determined in the presence or absence of $\mathrm{dG}$ from the set of reference compounds, respectively.

The slopes of the two different sets of plotted data provide the effective temperatures $[25,26]$ of 307.72 and 290.69 K, respectively, thus suggesting that the observed PA difference could be either due to an entropy effect, which affects at different extent the dissociation of the excited protonated dimers, or to the contribution, in the case of $(\mathrm{dA}-\mathrm{dG})$ protonated heterodimer, of an activation energy for the back reaction, which might be due to a difference in the protonation sites when $\mathrm{dG}$ is bound to the heterodimer or is present as a free protonated species $[\mathrm{dG}+\mathrm{H}]^{+}$.

Therefore, when tertiary amines and nucleosides, excluding $\mathrm{dG}$, are used as reference compounds, the maximum PA difference observed by applying eqs 1 and 2 is $0.10 \mathrm{kcal} / \mathrm{mol}$. The latter is within the experimental error of the kinetic method [18].

The data presented above are obtained from spontaneous unimolecular dissociation (MIKE spectra) of the appropriate dimers at the same $\mathrm{T}_{\text {eff }}{ }^{*}$ [18]. A different approach was therefore exploited [24] for the evaluation of the entropic term.

Different sets of nucleosides having a PA value around $237.00 \mathrm{kcal} / \mathrm{mol}$ were chosen as reference bases. The evaluation of the thermodynamic parameter is performed through the competitive dissociation of [ $\mathrm{N} \mathrm{H}$ $+\mathrm{dA}]^{+}$heterodimers produced by electrospray in a 


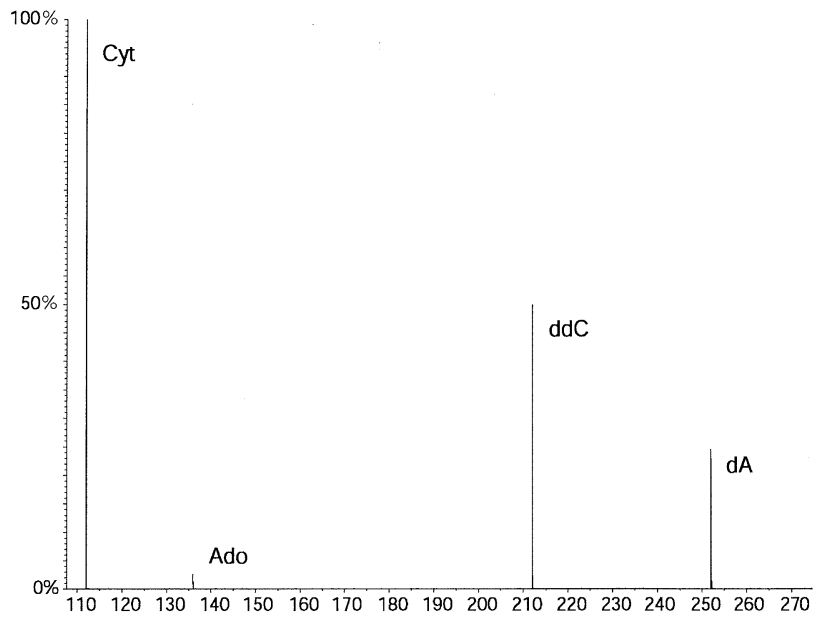

Figure 2. ESI CID spectra of the proton bound dimers [dA-H$\mathrm{ddC}]^{+}$recorded at CAD2.

Q $q$ TOF hybrid instrument. Different experimental conditions were set in the reaction chamber $(q)$ by varying the collision gas cell density.

The ESI-CID spectrum of $[\mathrm{dA}+\mathrm{H}+\mathrm{ddC}]^{+}$(Figure 2) showed the formation of the expected product ions
$[\mathrm{dA}+\mathrm{H}]^{+},[\mathrm{ddC}+\mathrm{H}]^{+}$, at $\mathrm{m} / \mathrm{z} 252$ and $\mathrm{m} / \mathrm{z} 212$, respectively, which undergo consecutive dissociations leading to the species [Cyt $+\mathrm{H}]^{+}$and $\left[\right.$Ado $+\mathrm{H}^{+}$at $\mathrm{m} / \mathrm{z} 112$ and $\mathrm{m} / \mathrm{z}$ 136, respectively. The latter must be considered in the evaluation of the kinetic constants of the competitive formation of the protonated $[\mathrm{N}+\mathrm{H}]^{+}$ monomers. Therefore $\mathrm{I}_{\mathrm{dA}}$, i.e., the ion current intensity (I) due to the partition of the proton on $\mathrm{dA}$, and $\mathrm{I}_{\mathrm{ddC}}$, due to the competitive process, are given by $\mathrm{I}_{\mathrm{dA}}=\mathrm{I}_{252}$ $+\mathrm{I}_{136}$ and $\mathrm{I}_{\mathrm{ddC}}=\mathrm{I}_{212}+\mathrm{I}_{112}$, respectively. These results allow to draw some preliminary observations on the dissociation kinetics of nucleoside proton-bound dimers. First of all, MIKE experiments on high kinetic energy ions provide threshold conditions for the determination of proton affinity by mass spectrometry. Secondly, when the internal energy of the reacting dimers is increased, the excess energy above the threshold for fragmentation is used by the initially formed product ions for further fragmentation, through the releasing of protonated nucleobase by glycosidic bond breakage. This behavior is common to all sets of proton-bound nucleoside pairs.

A, ddC, dCBz, and ddA (Table 3) are the nucleosides included in the first set of reference bases used to

Table 3. Experimental data for the determination of the proton affinity by ESI-MS/MS of dA

\begin{tabular}{|c|c|c|c|c|c|c|c|c|c|c|}
\hline \multirow[b]{2}{*}{ Ref. } & \multirow{2}{*}{$\frac{\ln \left(k_{\mathrm{dA}} / \mathrm{k}_{\mathrm{N}}\right.}{\mathrm{PA}(\mathrm{kcal} / \mathrm{mole})}$} & \multirow[b]{2}{*}{ CAD 2} & \multirow[b]{2}{*}{ CAD 3} & \multirow[b]{2}{*}{ CAD 4} & \multirow[b]{2}{*}{ CAD 5} & \multirow[b]{2}{*}{ CAD 6} & \multicolumn{4}{|c|}{ Plot ERR.STD.YX } \\
\hline & & & & & & & slope & Intercept & & $\mathrm{R}^{2}$ \\
\hline \multicolumn{11}{|l|}{ Set 1} \\
\hline A & 236.40 & 1.80 & 1.73 & 1.65 & 1.72 & 1.67 & -2.76 & -0.98 & 0,09 & 0.99 \\
\hline $\mathrm{ddC}$ & 237.60 & -1.71 & -1.40 & -1.36 & -1.47 & -1.31 & -2.65 & -0.93 & 0,11 & 0.98 \\
\hline $\mathrm{dC} \mathrm{Bz}$ & 237.65 & -1.90 & -1.97 & -1.81 & -1.82 & -1.83 & -2.59 & -0.92 & 0,07 & 0.99 \\
\hline \multirow[t]{2}{*}{$\mathrm{dd} A$} & 237.90 & -2.13 & -2.07 & -2.16 & -2.18 & -2.28 & -2.67 & -0.94 & 0,06 & 0.99 \\
\hline & & & & & & & -2.64 & -0.94 & 0,07 & 0.99 \\
\hline \multicolumn{11}{|l|}{ Set 2} \\
\hline$A$ & 236.40 & 1.80 & 1.73 & 1.65 & 1.72 & 1.67 & -2.61 & -0.44 & 0,29 & 0.98 \\
\hline $\mathrm{ddC}$ & 237.60 & -1.71 & -1.40 & -1.36 & -1.47 & -1.31 & -2.43 & -0.38 & 0,27 & 0.98 \\
\hline G & 236.80 & 0.30 & 0.23 & 0.21 & 0.17 & 0.12 & -2.42 & -0.41 & 0,25 & 0.99 \\
\hline \multirow[t]{2}{*}{ dd $A$} & 237.90 & -2.13 & -2.07 & -2.16 & -2.18 & -2.28 & -2.49 & -0.44 & 0,28 & 0.98 \\
\hline & & & & & & & -2.45 & -0.45 & 0,32 & 0.98 \\
\hline \multicolumn{11}{|l|}{ Set 3} \\
\hline A & 236.40 & 1.80 & 1.73 & 1.65 & 1.72 & 1.67 & -2.63 & -0.48 & 0,31 & 0.98 \\
\hline $\mathrm{dC} \mathrm{Bz}$ & 237.65 & -1.90 & -1.97 & -1.81 & -1.82 & -1.83 & -2.57 & -0.52 & 0,36 & 0.97 \\
\hline G & 236.80 & 0.30 & 0.23 & 0.21 & 0.17 & 0.12 & -2.52 & -0.53 & 0,36 & 0.99 \\
\hline \multirow[t]{2}{*}{ dd $A$} & 237.90 & -2.13 & -2.07 & -2.16 & -2.18 & -2.28 & -2.56 & -0.53 & 0,30 & 0.98 \\
\hline & & & & & & & -2.57 & -0.58 & 0,28 & 0.98 \\
\hline \multicolumn{11}{|l|}{ Set 4} \\
\hline A & 236.40 & 1.80 & 1.73 & 1.65 & 1.72 & 1.67 & -2.71 & -0.69 & 0,35 & 0.97 \\
\hline $\mathrm{dC} \mathrm{Bz}$ & 237.65 & -1.90 & -1.97 & -1.81 & -1.82 & -1.83 & -2.65 & -0.70 & 0,42 & 0.96 \\
\hline $\mathrm{dG}$ & 237.40 & -0.53 & -0.49 & -0.45 & -0.50 & -0.47 & -2.59 & -0.69 & 0,37 & 0.98 \\
\hline \multirow[t]{2}{*}{$d d A$} & 237.90 & -2.13 & -2.07 & -2.16 & -2.18 & -2.28 & -2.65 & -0.69 & 0,33 & 0.97 \\
\hline & & & & & & & -2.66 & -0.73 & 0,36 & 0.97 \\
\hline \multicolumn{11}{|l|}{ Set 5} \\
\hline A & 236.40 & 1.80 & 1.73 & 1.65 & 1.72 & 1.67 & -2.66 & -0.73 & 0,26 & 0.98 \\
\hline $\mathrm{dC} \mathrm{Bz}$ & 237.65 & -1.90 & -1.97 & -1.81 & -1.82 & -1.83 & -2.54 & -0.70 & 0,31 & 0.97 \\
\hline $\mathrm{ddC}$ & 237.60 & -1.71 & -1.40 & -1.36 & -1.47 & -1.31 & -2.48 & -0.69 & 0,23 & 0.98 \\
\hline $\mathrm{dd} A$ & 237.90 & -2.13 & -2.07 & -2.16 & -2.18 & -2.28 & -2.53 & -0.71 & 0,25 & 0.98 \\
\hline G & 237.40 & -0.53 & -0.49 & -0.45 & -0.50 & -0.47 & -2.50 & -0.73 & 0,28 & 0.98 \\
\hline
\end{tabular}

$\mathrm{dC}(\mathrm{PA}=236.2 \mathrm{kcal} / \mathrm{mol})$ [13]; ddC (PA $=237.6 \mathrm{kcal} / \mathrm{mol})$ [13]; $\mathrm{ddA}(\mathrm{PA}=237.9 \mathrm{kcal} / \mathrm{mol})$ [13]; $\mathrm{dG}(\mathrm{PA}=237.4 \mathrm{kcal} / \mathrm{mol})[21] ; \mathrm{A}(\mathrm{PA}=236.4 \mathrm{kcal} / \mathrm{mol})$ [13]; dC Bz (N-3-benzoyl-2'-deoxycytidine, PA $237.6 \mathrm{kcal} / \mathrm{mol}$ ) [19]. 


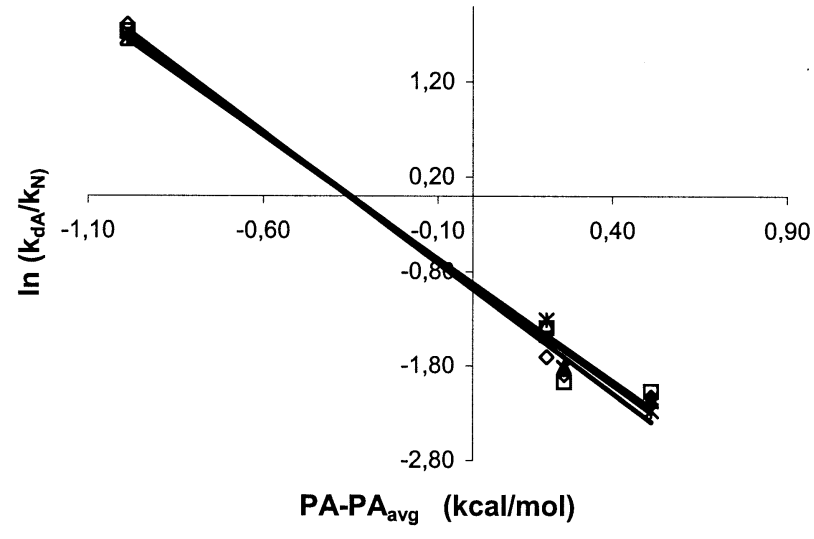

Figure 3. Evaluation of $-1 / \mathrm{RT}_{\text {eff }}$ and $\left(\mathrm{GB}_{\mathrm{app}}-\mathrm{PA}\right.$ avg $) 1 / \mathrm{RTeff}$ parameters at five different gas pressure relative to Set 1 .

calculate the PA of $\mathrm{dA}$ by means of the statistical approach (eq 3).

MS/MS experiments were carried out at five different collision gas-cell densities (CAD2, CAD3, CAD4, CAD5 and CAD6). The plot of $\ln \left(k / k_{N}\right)$ versus $P A_{a v g}$ for each experimental condition leads to a straight line (Figure 3) whose slopes represent the $\left(\mathrm{GB}_{\mathrm{app}}-\mathrm{PA}_{\mathrm{avg}}\right) /$ $\mathrm{RT}_{\text {eff }}$ value (Table 3, column 8 ), while the intercept corresponds to $-1 / \mathrm{RT}_{\text {eff }}$ value.

The effective temperatures determined in this case are 182.27 (CAD2), 189.69 (CAD3), 194.12 (CAD4), 188.80 (CAD5), and 190.13 K (CAD6). Linear regression coefficients of the corresponding kinetic plots (Figure 3; Table 3 column 9) are very close to unit and the standard deviation of the derived effective temperature corresponds to $4.29 \mathrm{~K}$ thus suggesting a very low entropy difference between the two competing reaction paths taken by each proton-bound nucleoside pairs. This method, based on a broad set of experimental conditions and on a more consistent data treatment, should represent, therefore, the most reliable approach for obtaining the PA value of $\mathrm{dA}$ by the kinetic method.

A statistical treatment of the data obtained by the slope of the weighted linear regression $\left(\mathrm{GB}_{\mathrm{app}}-\mathrm{PA}_{\mathrm{avg}}\right) /$ $\mathrm{RT}_{\text {eff }}$ versus $1 / \mathrm{RT}_{\text {eff }}$, which leads to PA-PA $\mathrm{Pavg}$, and by the intercept, corresponding to $-\Delta \mathrm{S} / \mathrm{R}$ (Figure 4 ), pro-

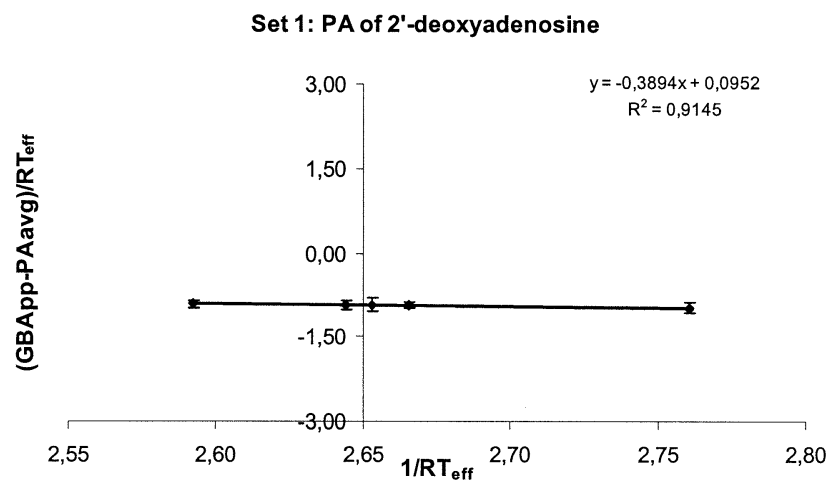

Figure 4. Evaluation of PA and $\Delta \Delta S$ for $\mathrm{dA}$ using Set 1.
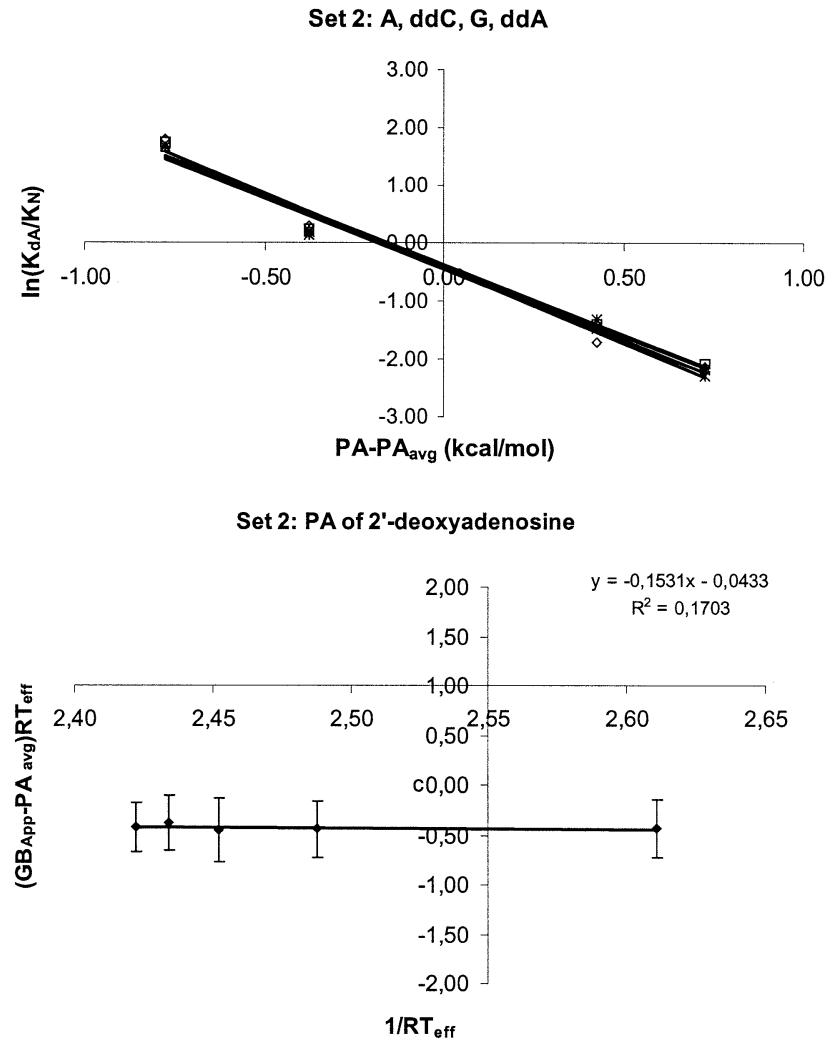

Figure 5. Kinetic method plots for determination of the proton affinity of dA based eq 3. (a) evaluation of $-1 / \mathrm{RT}_{\text {eff }}$ and (GB $\mathrm{Gapp}^{-}$ $\left.\mathrm{PA}_{\text {avg }}\right) 1 /$ RTeff and (b) PA and $\Delta \Delta \mathrm{S}$ for dA using the Set 2.

vided the values of $237.00 \pm 0.07 \mathrm{kcal} / \mathrm{mol}$ and of $-0.189 \mathrm{cal} / \mathrm{mol} \mathrm{K}$, for the PA of $\mathrm{dA}$ and $\Delta \Delta \mathrm{S}$ between the two competing dissociation channels, respectively. It is encouraging therefore that the first approach [11] in terms of data treatment, based however, on a careful selection of reference compounds, provides consistent PA value of an analytically more sophisticated method, where the base set is chosen with reference to their PA value, only.

In the second approach, however, some drawbacks might arise as well, especially when dealing with multibasic species such as nucleic acid molecules.

When, in fact, the set of reference nucleosides reported in Table 3, i.e., A, ddC, ddA, and G, was used to calculate the PA by the statistical approach, an extremely bad correlation $\left(\mathrm{R}^{2}=0.170\right.$, Figure $\left.5 \mathrm{~b}\right)$ was obtained in the plot of the slope versus intercept $\left(\left[\mathrm{GB}_{\mathrm{app}}-\mathrm{PA}_{\mathrm{avg}}\right] / \mathrm{RT}_{\mathrm{eff}}\right.$ versus $\left.1 / \mathrm{RT}_{\mathrm{eff}}\right)$. Even if the linear regression $\ln \left(\mathrm{k}_{\mathrm{dA}} / \mathrm{k}_{\mathrm{N}}\right)$ versus $\mathrm{PA}_{\mathrm{avg}}$, for each CAD condition was satisfactory $\left(\mathrm{R}^{2}=0.977 \div 0.985\right.$, Table 3 , Figure 5a).

The PA value is $237.02 \pm 0.20 \mathrm{kcal} / \mathrm{mol}$, while the estimated $\Delta \Delta \mathrm{S}$ is $0.086 \mathrm{cal} / \mathrm{mol} \mathrm{K}$. Similarly, the PA value obtained using $A, G, d C B z$, and $\operatorname{ddA}$ (Set 3) as reference base, is $237.64 \pm 0.41 \mathrm{kcal} / \mathrm{mol}$, while $\Delta \Delta \mathrm{S}=$ $-3.374 \mathrm{cal} / \mathrm{mol} \mathrm{K}$. The effective temperatures determined for these set of data at CAD $2 \div 6$ are 192.73, 
Table 4. PA values at each CAD condition using pairs of dimers

\begin{tabular}{llllll}
\hline CLUSTERS & CAD 2 & CAD 3 & CAD 4 & CAD 5 & CAD 6 \\
\hline \hline (dA-A)/(dA-ddC) & 237.02 & 237.06 & 237.06 & 237.05 & 237.07 \\
(dA-A)/(dA-dCBz) & 236.98 & 236.96 & 236.97 & 236.98 & 236.97 \\
(dA-A)/(dA-ddA) & 236.95 & 236.94 & 236.92 & 236.93 & 236.91 \\
(dA-A)/(dA-dG) & 237.17 & 237.18 & 237.19 & 237.17 & 237.18 \\
$(d A-A) /(d A-G)$ & 236.91 & 236.89 & 236.89 & 236.87 & 236.85
\end{tabular}

206.74, 207.75, 202.27, and 205.21 K, respectively. The standard deviation of $\mathrm{T}_{\text {eff }}$ is $6.07 \mathrm{~K}$. Once more and in agreement with FAB data, the PA is affected by the presence of guanosine. If $\mathrm{G}$ is replaced by $\mathrm{dG}$ as reference base (Set 4, Table 3, eq 3), the values thus determined $(\mathrm{PA}=237.33 \pm 0.22 \mathrm{kcal} / \mathrm{mol}, \Delta \Delta \mathrm{S}=$ $-1.533 \mathrm{cal} / \mathrm{mol} \mathrm{K}$ ) show that the proton affinity is closer to that obtained by the original method [11], whereas the entropy term is less determinant than when $G$ was used as reference compound.

Finally, the eq 1 was applied to determine the PA values at each CAD condition using different pairs of dimers (Table 4). The average values for the pairs $(\mathrm{dA}-\mathrm{A}) /(\mathrm{dA}-\mathrm{ddC}),(\mathrm{dA}-\mathrm{A}) /(\mathrm{dA}-\mathrm{dC} \mathrm{Bz}),(\mathrm{dA}-\mathrm{A}) /(\mathrm{dA}-$ $\mathrm{ddA}$ ) are 237.05, 236.97, and $236.93 \mathrm{kcal} / \mathrm{mol}$, respectively. When $\mathrm{dG}$ and $\mathrm{G}$ are used as partners, the average values are 237.18 and 236.88 , respectively.

The PA of $\mathrm{dA}$, evaluated by different analytical treatment of the kinetic data obtained from different sets of reference compounds and at different internal energy of the reactants, ranges from $237.00 \pm 0.07$ and $237.64 \pm 0.41 \mathrm{kcal} / \mathrm{mol}$ when guanine nucleosides are absent or present, respectively. The lower value is consistent to that determined at threshold energy (FABMIKE) with a set of tertiary amines $(237.0 \mathrm{kcal} / \mathrm{mol})$ [13]. A further important observation derives from the evaluation of the data obtained with the sets of reference compounds which include $G$ and $d G$. The two nucleosides share the same nucleobase but the latter has the higher PA value. The calculated $\Delta \Delta S$ for the competitive dissociation channels of the species $[\mathrm{dA}+\mathrm{dG}$ $+\mathrm{H}^{+}$is lower, absolute value, than that of the homologue $[\mathrm{dA}+\mathrm{G}+\mathrm{H}]^{+}$.

It can be considered, therefore, that even when the reference base interacts with a nucleoside more tightly than other reference compounds, the formation of multiple hydrogen bonds does not affect to a great extent the measured PA, since the dissociation energy of the bonds formed by the added proton with the interacting species is by far higher than any equivalent energy needed to break other weak interactions between the partners. This justifies the difference observed between the best and the worst correlation of data of 0.64 $\mathrm{kcal} / \mathrm{mol}$, which is closer to the experimental error [18]. Moreover, the higher is the proton affinity of one of the two nucleosides, while the lower is the entropic effect.

The PA of a given nucleoside can be obtained with less uncertainties if the references which show a bad correlation of data, such as $\mathrm{G}$ and $\mathrm{dG}$ in the case of $\mathrm{dA}$, are not considered.

The behavior of guanine nucleosides could be due to multiple interactions of Hoogst en type which might occur between the two purine bases, within the protonated cluster. This arrangement characterizes the interaction between cytosine nucleosides in protonated heterodimers which share the same nucleobase [20].

It cannot be excluded, however, that in some particular cases the basic sites interacting in the protonated dimer differ from those involved in the protonation of the released monomer. In this case the energetics of the competing dissociation pathways are affected to a certain extent by the contribution of the activation energy for the back reaction.

In conclusion, the experiments presented and discussed in the present work indicate that the PA of nucleosides determined by the kinetic method are not affected by uncertainties higher than any other experimental or theoretical method. As a matter of fact, the PA value of $\mathrm{dA}(237.0 \mathrm{kcal} / \mathrm{mol})$ reported in the literature is consistent with that determined here with the best set of data $(237.00 \pm 0.07 \mathrm{kcal} / \mathrm{mol})$.

\section{Acknowledgments}

The authors acknowledge funds from FIRB, Italian National Project and from the University of Calabria.

\section{References}

1. Biemann, K.; McCloskey, J. A. Application of Mass Spectrometry to Structure Problems. VI. Nucleosides. J. Am. Chem. Soc. 1962, 84, 2005-2007.

2. Little, D. P.; Aaserud, D. J.; Valaskovic, G. A.; McLafferty, F. W. Sequence Information from 42-108-mer DNAs (Complete for a 50 -mer) by Tandem Mass Spectrometry. J. Am. Chem. Soc. 1996, 118, 9352-9359.

3. Desiderio, D. M.; McCloskey, J. A.; Shaw, S. J.; Tsuboyama, K. Mass Spectrometry of Nucleic Acid Components. Analogs of Adenosine. J. Am. Chem. Soc. 1970, 92, 2510-2522.

4. Greco, F.; Liguori, A.; Sindona, G.; Uccella, N. Unimolecular Depurination of Protonated Deoxyribonucleosides in the GasPhase-A Fast-Atom-Bombardment Tandem Mass-Spectrometric Investigation. Org. Mass Spectrom. 1990, 25, 459-464.

5. Colacino, E.; Giorgi, G.; Liguori, A.; Napoli, A.; Romeo, R.; Salvini, L.; Siciliano, C.; Sindona, G. Structural Characterization of Isoxazolidinyl Nucleosides by Fast Atom Bombardment Tandem Mass Spectrometry. J. Mass Spectrom. 2001, 36, $1220-1225$.

6. Aaserud, G. A.; Little, D. P.; McLafferty, F. W.; Valaskovic, G. A. Sequence Information from 42-108-mer DNAs (Complete for a 50-mer) by Tandem Mass Spectrometry. J. Am. Chem. Soc. 1996, 118, 9352-9359.

7. Panico, M.; Sindona, G.; Uccella, N. Bio-organic Applications of Mass Spectrometry. 3. Fast-Atom-Bombardment-Induced Zwitterionic Oligonucleotide Quasimolecular Ions Sequenced by MS/MS. J. Am. Chem. Soc. 1983, 105, 5607-5610.

8. Gross, J.; Hillenkamp, F.; Wan, K. X.; Gross, M. L. Metastable Decay of Negatively Charged Oligodeoxynucleotides Analyzed with Ultraviolet Matrix-Assisted Laser Desorption/ Ionization Post-Source Decay and Deuterium Exchange. J. Am. Soc. Mass Spectrom. 2001, 12, 180-192. 
9. Wan, K. X.; Gross, J.; Hillemkamp, F.; Gross, M. L. Fragmentation Mechanism of Oligodeoxynucleotides Studied by H/D Exchange and Electrospray Ionization Mass Spectrometry. J. Am. Soc. Mass Spectrom. 2001, 12, 193-205.

10. Bowers, M. T.; Gidden, J. Gas-Phase Conformation of Deprotonated Trinucleotides $\left(\mathrm{dGGT}^{-}\right.$, $\mathrm{dTGT}^{-}$, and $\mathrm{dTTG}^{-}$): The Question of Zwitterionic Formation. J. Am. Soc. Mass Spectrom. 2003, 14, 161-170.

11. Greco, F.; Liguori, A.; Sindona, G.; Uccella, N. Gas-Phase Proton Affinity of Deoxyribonucleosides and Related Nucleobases by Fast-Atom-Bombardment Tandem Mass Spectrometry. J. Am. Chem. Soc. 1990, 112, 9092-9096.

12. Liguori, A.; Napoli, A.; Sindona, G. Determination of Substituent Effects on the Proton Affinities of Natural Nucleosides by the Kinetic Method. Rapid Mass Commun. Mass Spectrom. 1994, 8, 89-93.

13. Liguori, A.; Napoli, A.; Sindona, G. Survey of the Proton Affinities of Adenine, Cytosine, Thymine, and Uracil Dideoxyribonucleosides, Deoxyribonucleosides, and Ribonucleosides. J. Mass Spectrom. 2000, 35, 139-144.

14. http://www.isinet.com.

15. Russo, N.; Toscano, M.; Grand, A.; Jolibois, F. Protonation of Thymine, Cytosine, Adenine, and Guanine DNA Nucleic Acid Bases: Theoretical Investigation into the Framework of Density Functional Theory. J. Comput. Chem. 1998, 19, 989-1000.

16. Cooks, R. G.; Patrick, J. S.; Kotiaho, T.; McLuckey, S. A. Thermochemical Determinations by the Kinetic Method. Mass Spectrom. Rev. 1994, 13, 287-339.

17. Cooks, R. G.; Kruger, T. L. Intrinsic Basicity Determination Using Metastable Ions. J. Am. Chem. Soc. 1977, 99, 1279-1281.

18. Drahos, L.; Vékey, K. Entropy Evaluation Using the Kinetic Method: Is It Feasible? J. Mass Spectrom. 2003, 38, 1025-1042.
19. Di Donna, L.; Napoli, A.; Sindona, G. Entropy Effect in the Evaluation of the Proton Affinity of N-3-Benzoyl-2-Deoxycytidines by the Kinetic Method. Int. J. Mass Spectrom. 2001, 210/211, 165-172.

20. Armentano, D.; De Munno, G.; Di Donna, L.; Giorgi, G.; Napoli, A.; Salvini, L.; Sindona, G. Self-Assembling of Cytosine Nucleoside into Triply-Bound Dimers in Acid Media. A Comprehensive Evaluation of Proton-Bound Pyrimidine Nucleosides by Electrospray Tandem Mass Spectrometry, X-rays Diffractometry, and Theoretical Calculations. J. Am. Soc. Mass Spectrom. 2004, 2, 268-279.

21. Cheng, X.; Wu, Z.; Fenselau, C. Collision Energy Dependence of Proton-Bound Dimer Dissociation: Entropy Effects, Proton Affinities, and Intramolecular Hydrogen-Bonding in Protonated Peptides. J. Am. Chem. Soc. 1993, 115, 4844-4848.

22. Cerda, B. A.; Wesdemiotis, $\mathrm{C}$. $\mathrm{Li}+, \mathrm{Na}+$, and $\mathrm{K}+$ binding to the DNA and RNA Nucleobases. Bond Energies and Attachment Sites from the Dissociation of Metal Ion-Bound Heterodimers. J. Am. Chem. Soc. 1996, 118, 11884-11892.

23. Armentrout, P. B. Entropy Measurements and the Kinetic Method: A Statistically Meaningful Approach. J. Am. Soc. Mass Spectrom. 2000, 11, 371-379.

24. Shaw, B. R.; Williams, N. G.; Williams, L. D. Dimers, Trimers, and Tetramers of Cytosine with Guanine. J. Am. Chem. Soc. 1989, 111, 7205-7209.

25. Drahos, L.; Vekey, K. Special Feature: Commentary-How Closely Related are the Effective and the Real Temperature. J. Mass Spectrom. 1999, 34, 79-84.

26. Ervin, K. M. Microcanonical Analysis of the Kinetic Method. The Meaning of the "Effective Temperature." Int. J. Mass Spectrom. 2000, 196, 271-284. 